\title{
PICTURE OF THE MONTH \\ Orographic Fibrous Plumes Over New England
}

JOHN H. CONOVER-Air Force Cambridge Research Laboratories, Bedford, Mass.

\begin{abstract}
The enhancement of cirrus cloudiness by orographic effects along the periphery of a large-scale thin cirrus cloud system is illustrated. From radiometric measurements and comparison with a nearby sounding, it was found that the cloud tops coincided with the tropopause.
\end{abstract}

Their high emissivity suggests cloud condensation in liquid form, which quickly freezes to form long ice-crystal plumes. These crystals may have seeded a supercooled liquid-droplet low cloud to cause snow at the ground.
A fine example of orographic cloudiness at high levels is shown in figure 1, the visible (fig. 1A) and infrared (IR) imagery (fig. 1B) derived from the very high resolution radiometers (VHRR) aboard NOAA 2. These photographs cover upper New York State, New England, and adjacent portions of Canada.

The land is covered with snow except for southern New England, western New York, and a part of Canada north of Lake Ontario. This is deduced from the white background over the unforested areas in figure $1 \mathrm{~A}$ and the darker land areas in figure $1 \mathrm{~B}$, which correspond to relatively warm, bare landmasses. Central New England and New York State are covered with scattered to broken stratocumulus wave clouds and cumulus cloud streets. These are indicative of winds, more or less parallel to the cloud streets, with speeds increasing with height from the surface to cloud level, a steep lapse rate, and an inversion at cloud-top level. Details that lead to this interpretation have been given by the author (Conover 1964a, 1964b). In this case, the wind direction was deduced as blowing from left to right in the figure (or from the west-northwest) because a cloud vortex was present to the northeast, outside the region shown in the figure.

The orographically enhanced high clouds, which have been described and classified as fibrous plumes by Conover $(1964 b)$, are shown over northern New England. These clouds are on the southern periphery of a widespread, thin cirrus and cirrostratus cloud system associated with the old vortex to the northeast. Cross sections (fig. 2) along lines $\mathrm{AA}$ and $\mathrm{BB}$ in figure $1 \mathrm{~B}$ show the topography and cloud distributions based on the observations that follow. Note that some of the stations reporting clouds and weather are to the side of the cross section lines as shown in figure 1B. Cirrus is first enhanced over and to the lee of Whiteface Mountain [1.5 km above mean sea level (MSL)] in the Adirondack Mountains shown in section AA. The next primary zone of enhancement, moving downwind toward the east, is over the second ridge of mountains in Vermont shown at the start of section BB. In this area, the westernmost north-south ridge of the Green Mountains rises about $1.0 \mathrm{~km}$ from the broad valley and lake to the west; it is followed by a valley and second ridge averaging $0.9 \mathrm{~km}$ MSL to the east. Farther east, more cirrus forms over and east of the White Mountains (1.5-1.9 km MsL). The plume extends roughly $230 \mathrm{~km}$ downwind from the White Mountains.

Radiative temperatures were derived from the locally acquired direct readout scanning radiometer (DRSR) imagery from the same orbit. The method makes use of a temperature-photographic density relationship, which can be developed for each photograph.

The radiative temperature of the thickest part of the cirrus plume was $-49^{\circ} \mathrm{C}$. A temperature of $-11^{\circ} \mathrm{C}$ was found for the top of the stratocumulus; however, this value is probably high because the measurement covered a relatively large area and, therefore, included thin spots or holes in the cloud and, consequently, higher radiative temperatures from below. A temperature of $0^{\circ} \mathrm{C}$ was found for Lake Ontario, a reasonable value for the lake at this time of the year.

The Portland, Maine (PWM), 1200 GMT sounding (also shown in fig. 2) shows a nearly adiabatic lapse rate to 1.8 $\mathrm{km}$, an inversion to $2.0 \mathrm{~km}$, and a continuing steep lapse rate to the tropopause at $8.2 \mathrm{~km}$. The tropopause temperature was $-48^{\circ} \mathrm{C}$. At the base of the lower inversion, presumably near the top of the stratocumulus, the temperature was $-15^{\circ} \mathrm{C}$; an aircraft $90 \mathrm{~km}$ southwest of Portland at 1500 GMT reported these cloud tops at $2.0 \mathrm{~km}$. Wind directions ranged from $270^{\circ}$ at $1.0 \mathrm{~km}$ to $300^{\circ}$ at $8.0 \mathrm{~km}$, and wind speeds increased to $20 \mathrm{~m} / \mathrm{s} \mathrm{at} 2.0 \mathrm{~km}$ from $5 \mathrm{~m} / \mathrm{s}$ near the ground. A maximum of $24 \mathrm{~m} / \mathrm{s}$ was measured at $6.0 \mathrm{~km}$. Surface reports showed cirrus and cirrostratus (and even a halo) in addition to the lower clouds. Weather radar observations at 1435 GMT showed an area of snow showers, marked by the triangular area in figure $1 \mathrm{~B}$, topped at $2.0 \mathrm{~km}$ under the thick plume eastnortheast of the White Mountains. In that area, light 

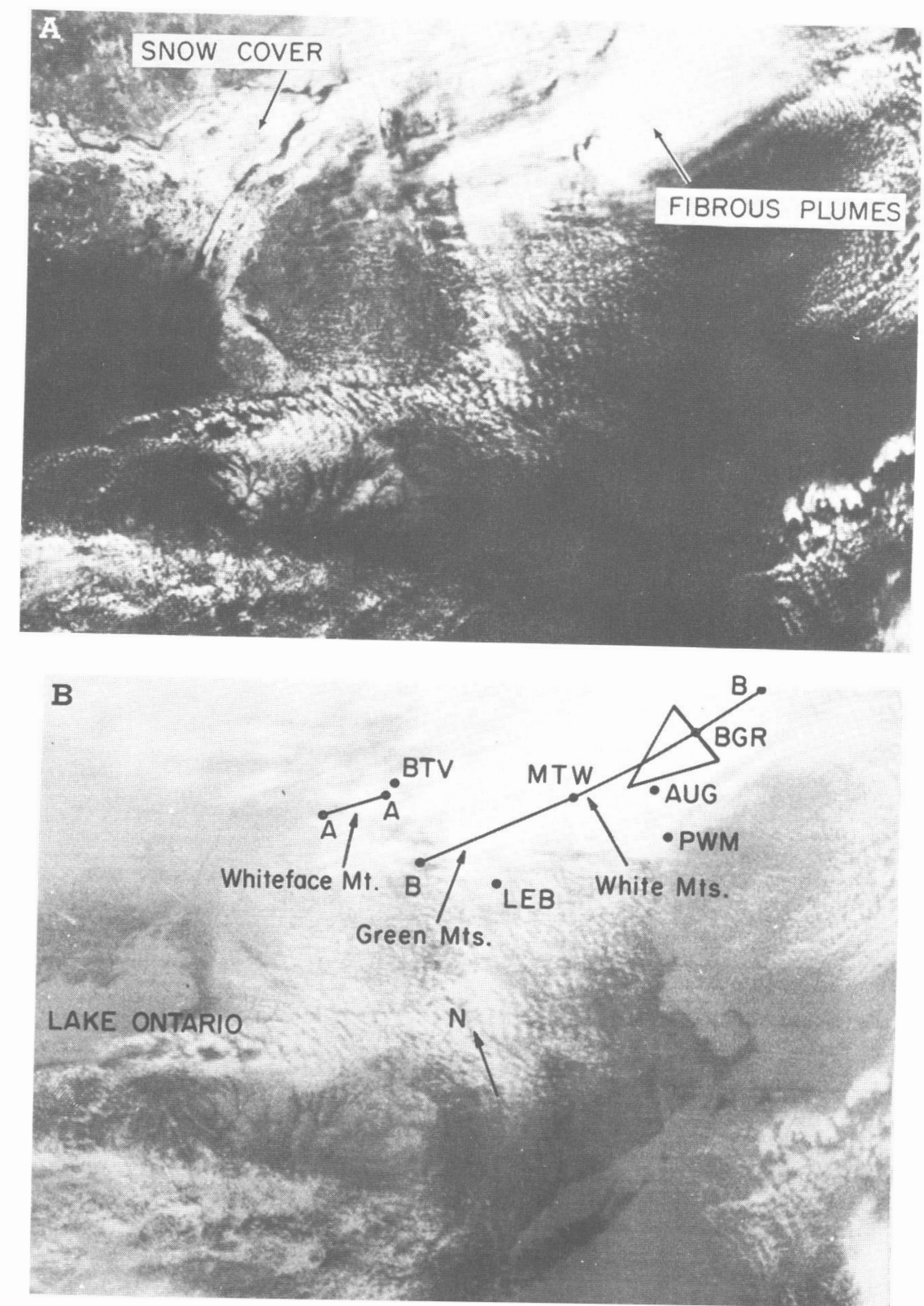

FIqURE 1.-NOAA 2 satellite (A) visible imagery and (B) IR imagery for 1448 GMT on Apr. 12, 1973. The observing station call letters, cross-section lines, and place names are shown. Within the triangle is an area of snow showers observed by weather radar.

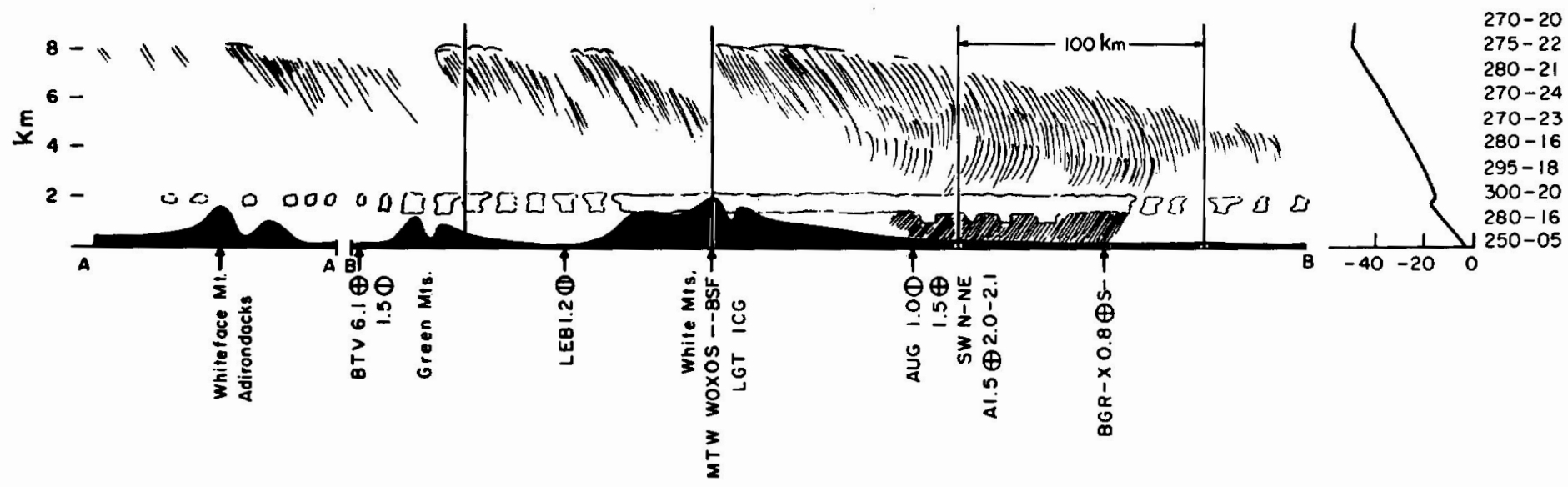

Figdre 2.-Cross sections depicting clouds along lines AA and BB in figure 1. The Portland, Maine, temperature sounding ( $\left.{ }^{\circ} \mathrm{C}\right)$, wind direction $\left({ }^{\circ}\right)$, and speed $(\mathrm{m} / \mathrm{s})$ are shown on the right. 
snow reached the ground. An aircraft on the southern edge of this precipitation area reported an overcast base of 1.5 $\mathrm{km}$ and top at 2.0 to $2.1 \mathrm{~km}$.

In summary, the pictures and other data illustrate a case of orographically enhanced cirrus on the periphery of a large-scale thin cirrus cloud system. The clouds were probably topped at the tropopause $(8.2 \mathrm{~km} \mathrm{MSL})$; they developed over or slightly downwind of landmasses that rose 1.0 to $1.5 \mathrm{~km}$ above the general level of the terrain. The fact that the radiative temperature of the top of the cirrus was within $1^{\circ} \mathrm{C}$ of the lowest temperature of the sounding indicates a high emissivity or high optical thickness. The cloud, therefore, is not only thick vertically but very likely contains water droplets, even in its upper levels, which quickly freeze to form the long plumes of ice crystals. Scattered to broken stratocumulus wave clouds surrounded the area; but under at least a portion of the plume, they merged to form a solid layer topped near $2.0 \mathrm{~km}$. An extensive area of light snow fell from a portion of this stratocumulus overcast, which was under the plume. It is quite possible that this supercooled cloud was naturally seeded from the overlying ice cloud plume, although no reports exist that describe the base of the fibrous plume.

\section{ACKNOWLEDGMENT}

Original photographs were supplied by the National Environmental Satellite Service, NOAA, whose cooperation is gratefully acknowleged.

\section{REFERENCES}

Conover, John H., "Lee Wave Clouds Photographed From an Aircraft and a Satellite," Weather, Vol. 19, No 3, London, England, Mar. 1964a, pp. 79-92.

Conover, John H., "The Identification and Significance of Orographically Induced Clouds Observed by TIROS Satellites," Journal of Applied Meteorology, Vol. 3, No. 3, June 1964b, pp. 226-234. 